\title{
FEKUNDITAS OPTIMAL IKAN RAINBOW BOESMANI (Melanotaenia boesemani) DENGAN PERBANDINGAN BEBERAPA UKURAN
}

\author{
Iqbal Mujadid $^{1}$, Ediyanto $^{1}$, Nurhidayat ${ }^{2}$ \\ 1. Fakultas Perikanan dan Ilmu Kelautan USNI \\ 2. Balai Penelitian dan Pengembangan Budidaya Ikan Hias, KKP
}

\begin{abstract}
Research on fecundity optimal boesman's rainbowfish. Treatment from the point of view of the differences in the size of fish which is long p1 $(3,0-3,9 \mathrm{~cm}), \mathrm{p} 2$ $(4,0-4,9 \mathrm{~cm}), \mathrm{p} 3(5,0-5,9 \mathrm{~cm}), \mathrm{p} 4(6,0-6,9 \mathrm{~cm})$, and p5 (7,0-7,9cm ). The research uses design random complete 5 treatment and 6 repeat, if there were differences in treatment in the further by LSD test to know the differences in each treatment. The main parameters measured is the number of eggs total and relative and the gonad maturity level visually and microscopic. Treatment of five and six repeat was done, yields fish with a long 7,0-7,9 $\mathrm{cm}$ get the best result is fecundity a total 367 grains and fecundity relatively were 81 grains. The level of maturity the gonads highest obtained from 5th treatment that is long 7,0-7,9 $\mathrm{cm}$ parent with a maturity of the gonads stadium five.
\end{abstract}

Keyword : rainbow boesmani, fecundity, gonads maturity level.

\begin{abstract}
Abstrak
Penelitian tentang fekunditas optimal ikan Rainbow Boesmani. Perlakuan dilihat dari perbedaan ukuran yaitu panjang ikan P1(3-3,9cm), P2(4-4,9cm), P3(5$5,9 \mathrm{~cm}), \mathrm{P} 4(6-6,9 \mathrm{~cm})$, dan P5(7-7,9cm). Penelitian menggunakan Rancangan Acak Lengkap (RAL) 5 perlakuan dan 6 ulangan, apabila terdapat perbedaan pada perlakuan di uji lanjut dengan Uji BNT untuk mengetahui perbedaan pada tiap-tiap perlakuan. Parameter utama yang diukur adalah jumlah telur baik total maupun relatif dan tingkat kematangan gonad secara visual dan mikroskopis. Dari kelima perlakuan dan enam kali ulangan yang dilakukan, menghasilkan panjang ikan dengan ukuran $7-7,9 \mathrm{~cm}$ mendapatkan hasil terbaik yaitu fekunditas total sebanyak 367 butir dan fekunditas relatif sebanyak 81 butir. Tingkat kematangan gonad tertinggi diperoleh dari perlakuan ke-5 yaitu panjang induk $7-7,9 \mathrm{~cm}$ dengan tingkat kematangan gonad stadium lima (TKG-5)
\end{abstract}

Kata kunci : Rainbow Boesmani, fekunditas, tingkat kematangan gonad. 


\section{Pendahuluan}

Ikan hias merupakan salah satu komoditas andalan baru yang masih memerlukan upaya penanganan untuk pengembangan yang lebih intensif di Indonesia. Hal tersebut berakitan dengan potensi pasar internasional yang prospektif dan dukungan sumber daya yang melimpah. Pada tahun 2013, dari target produksi sebesar 1,1 miliar ekor, sampai dengan bulan Desember 2013 tercapai 1,04 miliar ekor atau 94,26\%. Wilayah produksi ikan hias Indonesia tersebar di 18 Propinsi di seluruh Indonesia, dengan sentra budidaya ikan hias terbesar terdapat di Jawa Timur, Jawa Barat, DKI Jakarta, Banten dan D.I. Yogyakarta. (KKP.go.id, 2014)

Berdasarkan data dari United Nation Commodity Trade Statistics Database, nilai ekspor ikan hias Indonesia pada tahun 2012 meningkat sebesar US\$ 21,015 juta, atau 8,12\% dari total nilai ekspor ikan hias di dunia yang mencapai US\$258,8 juta, sehingga Indonesia menempati posisi kelima di bawah Singapura, Spanyol, Jepang, dan Malaysia. (www.comtrade.un.org, 2014 ).

Permasalahan yang diangkat dalam penelitian ini berasal dari pembenihan ikan hias Rainbow Boesemani (Melanotaenia boesemani) yang telah dilakukan sebelumnya, dimana fekunditas ikan Rainbow Boesmani lebih rendah dari hasil pembanding. Hal ini diduga karena ikan Rainbow Boesmani yang dipijahkan baru pertama kali memijah dengan rata-rata ukuran di kisaran $3-4 \mathrm{~cm}$, selain itu ikan Rainbow Boesmani masuk kategori terancam keberadaannya di alam menurut IUCN Red List (1994) karena ikan Rainbow Boesmani di alam hidup terisolir di tiga danau di daerah Papua yang rentan dengan eksploitasi manusia sehingga kelangsungan spesienya perlu dipertahankan melalui proses budidaya.

\section{Metodologi}

Kegiatan penelitian ini akan dilaksanakan selama empat Bulan mulai dari Bulan Mei sampai Agustus 2015 yang bertempat di Balai Penelitian dan Pengembangan Budidaya Ikan Hias, Jalan Perikanan No. 13 Pancoran Mas Depok. Peralatan yang akan digunakan adalah keperluan yang dipergunakan selama penelitian, baik yang berasal dari fasilitas BPPBIH, pengadaan pribadi, maupun pihak lain yang membantu hingga terlaksananya seluruh metode yang dijalani. Bahan yang akan digunakan dalam penelitian ini adalah pakan yang diberikan selama persiapan induk dan proses pemijahan yaitu cacing darah (Chironomus Sp.) untuk menunjang pertumbuhan dan kematangan gonadnya. Ikan Rainbow Boesmani (Melanotaenia boesemani) yang digunakan dalam penelitian ini adalah benih ikan yang berasal dari Balai Penelitian dan Pengembangan Budidaya Ikan Hias Depok, kios dan pasar ikan hias dengan ukuran 3,0-7,9 cm dengan mengesampingkan faktor pengalaman indukan tersebut memijah. 
Metode yang digunakan dalam penelitian adalah metode eksperimen dengan analisis rancangan acak lengkap (RAL) satu faktor dengan 5 perlakuan ukuran induk serta 6 ulangan. Sehingga jumlah suatu percobaan adalah 30 unit akuarium dengan padat tebar 1 ekor jantan dan 1 ekor betina, pemeliharaan dilakukan didalam ruangan terkontrol. perlakuan ini menggunakan perbedaan panjang indukan.

$$
\mathbf{Y i j}=\boldsymbol{\mu}+\mathbf{t i}+\mathbf{e i j}
$$

Yij : Data hasil pengamatan pada perlakuan ke-i dan ulangan ke-j

$\mu \quad$ : Nilai tengah dari pengamatan

ti : Pengaruh aditif dari perlakuan ke-i

eij : Pengaruh galat hasil percobaan pada perlakuan ke-i dan ulangan

ke-j (Steel dan Torrie,1991)

Kualitas air yang diamati sejak tahap pemeliharaan induk sampai tahap perlakuan dilakukan 7 hari sekali. Pengamatan perkembangan gonad yang dilakukan dengan membuat preparat histologis ovarium. Pengamatan dilakukan 3 kali pada tiap-tiap sampel perlakuan yaitu saat awal seleksi induk, saat pemeliharaan induk dan saat pemijahan.

Data yang diperoleh selanjutnya dianalisis ragam (ANOVA) untuk mengetahui pengaruh ukuran terhadap fekunditas. Apabila terdapat perbedaan akan di uji lanjut (BNT) untuk melihat perlakuan terbaik.

$$
B N t_{\alpha}=\left(t_{\alpha, d f_{e}}\right) \cdot \sqrt{\frac{2\left(M S_{E}\right)}{r}}
$$

Parameter yang dianalisis yaitu tingkat kematangan gonad, fekunditas, derajat pembuahan, dan derajat penetasan.

\section{Hasil dan Pembahasan}

Hasil yang diperoleh berdasarkan pengukuran, pengamatan dan uji yang dilakukan diuraikan sebagai berikut.

Tabel Bobot Induk

\begin{tabular}{|c|c|c|c|}
\hline \multirow{2}{*}{ Perlakuan } & \multicolumn{3}{|c|}{$\begin{array}{c}\text { Berat Induk } \\
(\mathbf{m g})\end{array}$} \\
\cline { 2 - 4 } & H0 & H10 & H20 \\
\hline $\mathrm{P}_{1}$ & 550 & 570 & 1000 \\
\hline $\mathrm{P}_{2}$ & 1100 & 1300 & 1500 \\
\hline $\mathrm{P}_{3}$ & 2300 & 2400 & 3280 \\
\hline $\mathrm{P}_{4}$ & 3400 & 3900 & 4030 \\
\hline $\mathrm{P}_{5}$ & 4900 & 5200 & 6410 \\
\hline
\end{tabular}


Penimbangan bobot induk sejak $\mathrm{H}_{0}$ pemeliharaan induk sampai $\mathrm{H}_{20}$ dengan pemberian pakan chironomus menunjukan peningkatan pada bobot induk.

Tingkat kematangan gonad baik secara visual maupun mikroskopis menunjukan perbedaan nyata pada tiap-tiap perlakuan. Pada gambar 2 dan 3
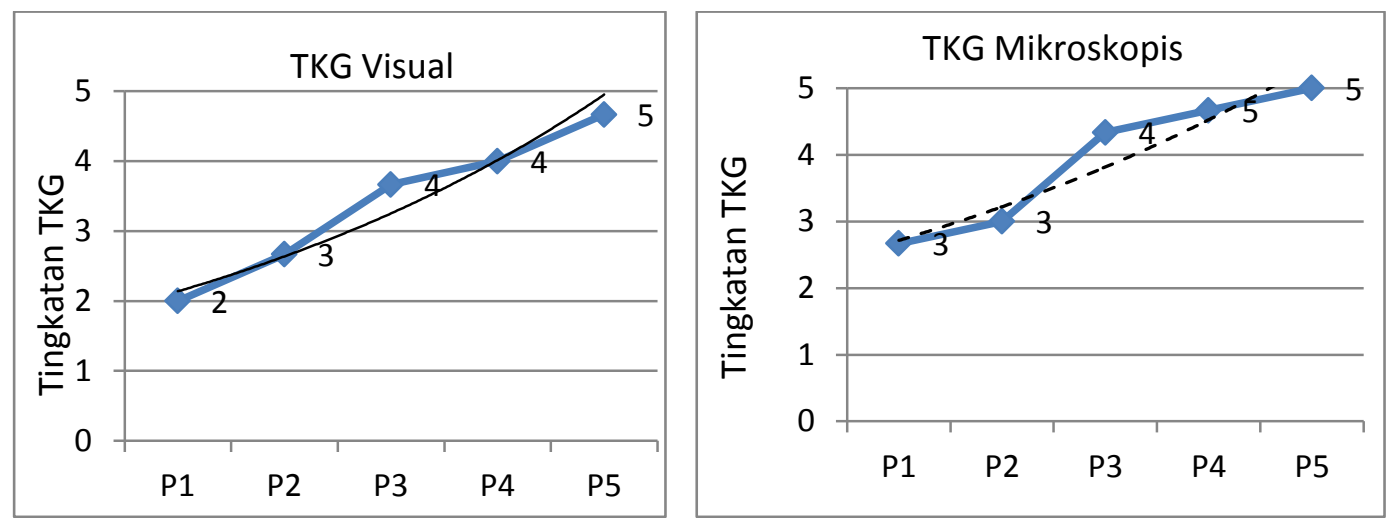

Grafik menunjukan bahwa semakin panjang induk ikan rainbow boesmani, maka semakin tinggi tingkat kematangan gonad nya. Hasil ANNOVA dari Uji Rancangan Acak Lengkap yaitu pengamatan TKG secara visual diperoleh pelakuan ke-5 panjang ikan $7-7,9 \mathrm{~cm}$ sebagai perlakuan terbaik sesuai dengan pernyataan Pusey et al (2011) Ovari-ovari berwarna kuning oranye dengan beberapa tembus cahaya sekeliling telur-telur globul-globul minyak membentuk massa tunggal terpolarisasi.

Berdasarkan hasil pengamatan mikroskopis tingkat kematangan gonad ikan Rainbow Boesmani, didapatkan hasil terbaik pada perlakuan ke-5 yaitu ikan dengan ukuran 7-7,9cm, sesuai dengan pernyataan Chinabut et al, (1991). Oosit stadium matang ditandai dengan oosit membulat dan ditandai warna merah muda terang dan terdapat beberapa inti sel yang sudah bermugrasi, dinding sel menipis.

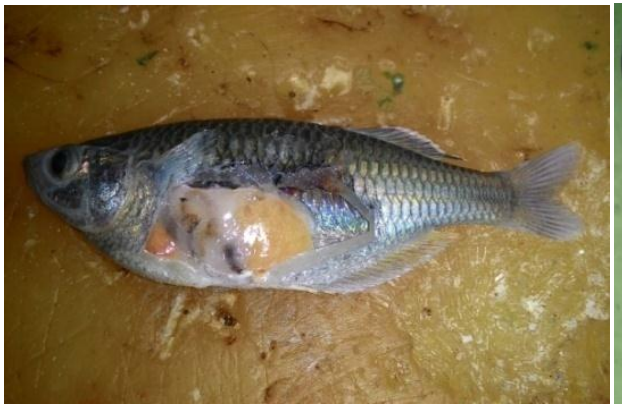

Gambar 8. TKG Visual

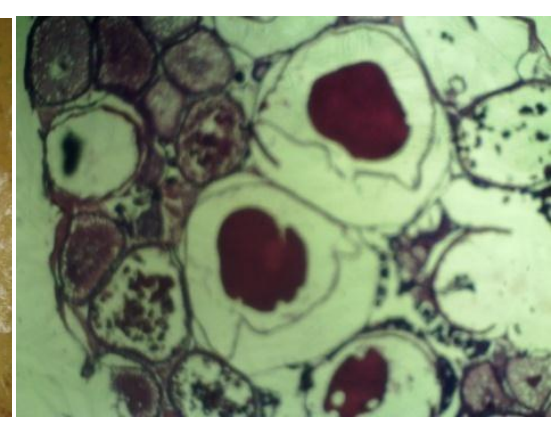

Gambar 9. TKG Mikroskopis

Perbandingan antara bobot induk dengan bobot gonad tidak berpengaruh nyata terhadap perlakuan panjang indukan. Berat bobot gonad meningkat seiring dengan meningkatnya bobot ikan 


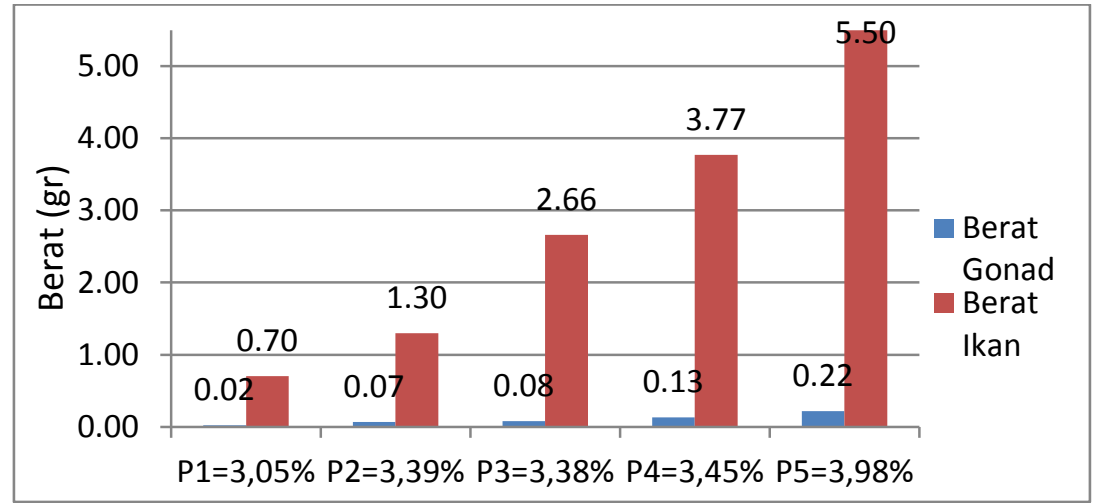

Sesuai dengan pernyataan Effendie (1997) bahwa gonad ikan semakin bertambah berat diimbangi dengan bertambah besar ukurannya, karena sebagian besar hasil metabolisme tertuju untuk perkembangan gonad. Woynarovich \& Horvath (1980) menyatakan bahwa jumlah telur ikan dapat dipengaruhi oleh bobot tubuh induk betina dan ukuran diameter telur.

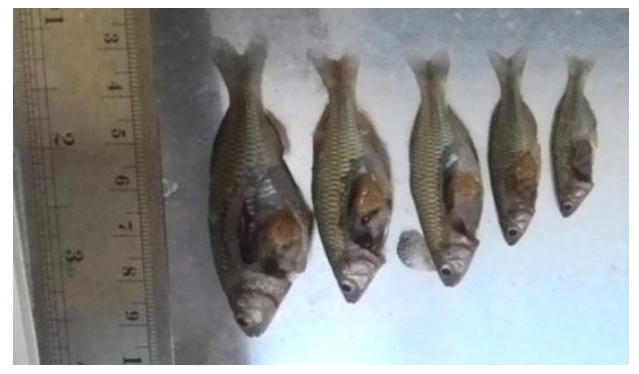

Perlakuan panjang indukan berpengaruh terhadap diameter telur induk ikan Rainbow boesmani menunjukan perbedaan yang nyata dan sangat nyata, sesuai dengan pernyataan Bastiar (2011) bahwa ikan pelangi dengan ukuran kecil memiliki rata-rata diameter telur yang kecil, sedangkan ikan pelangi yang berukuran besar rata-rata diameter telurnya lebih besar, dengan demikian, diameter telur terbesar yaitu $1,15 \mathrm{~mm}$ terdapat pada perlakuan ke-5 yaitu ikan dengan panjang $7-7,9 \mathrm{~cm}$.

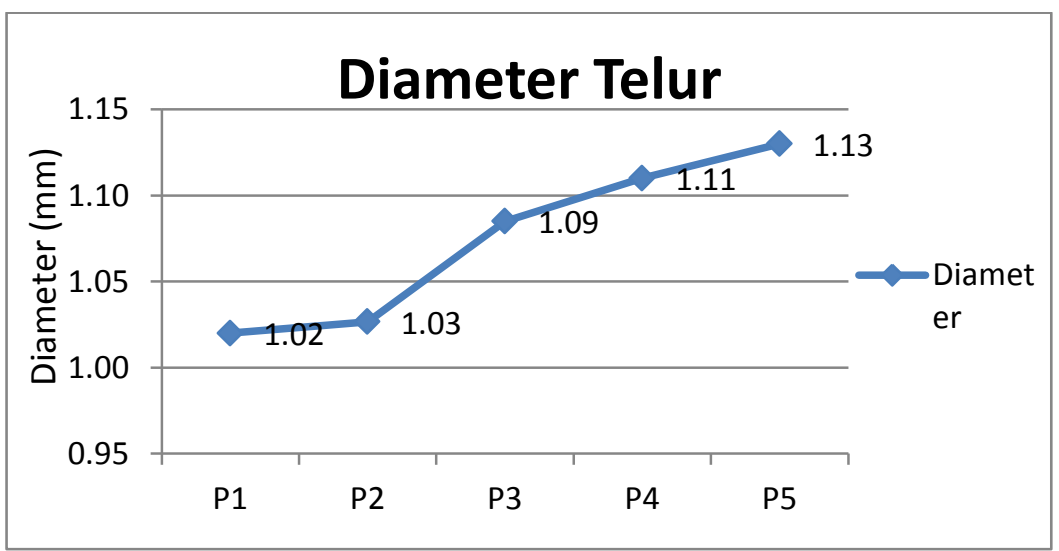


Perlakuan perbedaan panjang indukan berpengaruh nyata terhadap fekunditas ikan Rainbow Boesmani, baik fekunditas total maupun relatif sesuai dengan pernyataan Wotton, 1979 bahwa Pertambahan panjang tubuh ikan akan meningkatkan jumlah fekunditas, karena rongga tubuh tempat ovari akan semakin besar.

Tappin (2010), menambahkan bahwa jumlah telur yang dikeluarkan oleh satu ekor betina berkaitan dengan ukurannya, jumlah total telur yang dikeluarkan akan meningkat seiring meningkatnya ukuran serta tingkat kematangan gonadnya. Data yang dihasilkan menunjukan perlakuan ke-5 ikan dengan panjang $7-7,9 \mathrm{~cm}$ adalah perlakuan dengan jumlah fekunditas total dan relatif terbanyak.
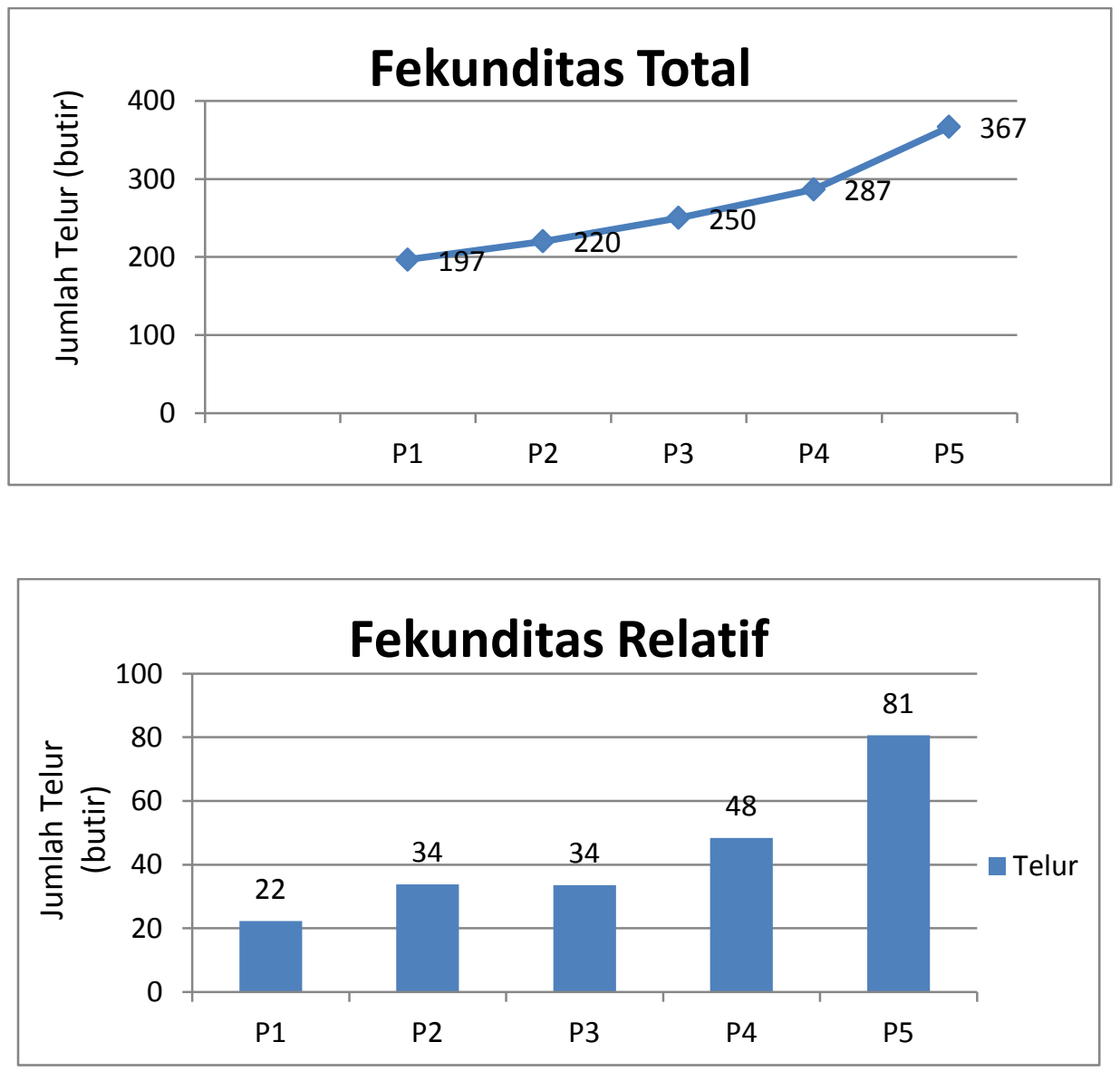

Derajat pembuahan dan penetasan telur ikan Rainbow Boesmani terlihat cukup tinggi dengan nilai rata-rata $94,3 \%$ untuk derajat pembuahan pada seluruh perlakuan dan $88,7 \%$ untuk nilai rata-rata derajat penetasan pada seluruh perlakuan, sesuai dengan hasil pembanding pada domestikasi ikan pelangi oleh Bastiar Nur (2011) yaitu $98,81 \%$ pada pembuahan dan $84,86 \%$ untuk penetasan. 
Tabel Fertilitas Telur

\begin{tabular}{|c|c|c|c|c|}
\hline Perlakuan & $\begin{array}{c}\text { Fekunditas } \\
\text { (butir) }\end{array}$ & $\begin{array}{c}\text { Fertil } \\
\text { (butir) }\end{array}$ & $\begin{array}{c}\text { Infertil } \\
\text { (butir) }\end{array}$ & $\begin{array}{c}\text { Pembuahan } \\
(\boldsymbol{\%})\end{array}$ \\
\hline $\mathrm{P}_{1}$ & 67 & 63 & 4 & 94,03 \\
\hline $\mathrm{P}_{2}$ & 135 & 124 & 11 & 91,85 \\
\hline $\mathrm{P}_{3}$ & 201 & 195 & 6 & 97,01 \\
\hline $\mathrm{P}_{4}$ & 242 & 229 & 13 & 94,63 \\
\hline $\mathrm{P}_{5}$ & 484 & 455 & 29 & 94,01 \\
\hline & & & Rata-rata & $\mathbf{9 4 , 3 1}$ \\
\hline
\end{tabular}

Tabel Penetasan Telur

\begin{tabular}{|c|c|c|c|c|}
\hline Perlakuan & $\begin{array}{c}\text { Fertil } \\
\text { (butir) }\end{array}$ & $\begin{array}{c}\text { Menetas } \\
\text { (butir) }\end{array}$ & $\begin{array}{c}\text { Tidak Menetas } \\
\text { (butir) }\end{array}$ & $\begin{array}{c}\text { Penetasan } \\
(\boldsymbol{\%})\end{array}$ \\
\hline $\mathrm{P}_{1}$ & 63 & 50 & 13 & 79,37 \\
\hline $\mathrm{P}_{2}$ & 124 & 101 & 23 & 81,45 \\
\hline $\mathrm{P}_{3}$ & 195 & 180 & 15 & 92,31 \\
\hline $\mathrm{P}_{4}$ & 229 & 220 & 9 & 96,07 \\
\hline $\mathrm{P}_{5}$ & 455 & 429 & 26 & 94,29 \\
\hline & & & Rata-rata & $\mathbf{8 8 , 7 0}$ \\
\hline
\end{tabular}

Hasil pengamatan dan pengukuran kualitas air dari ketujuh parameter yang diukur menunjukan bahwa kualitas air selama pemeliharaan dan pemijahan masih dalam batas toleransi ikan tersebut, sehingga parameter kualitas air selama masa pemeliharaan sampai pemijahan masih dalam kondisi layak untuk kehidupan dan perkembangbiakan ikan Rainbow Boesmani.

\begin{tabular}{cccccc}
\hline \multirow{2}{*}{ Parameter } & \multicolumn{5}{c}{ Perlakuan } \\
\cline { 2 - 6 } & $\mathbf{P}_{\mathbf{1}}$ & $\mathbf{P}_{\mathbf{2}}$ & $\mathbf{P}_{\mathbf{3}}$ & $\mathbf{P}_{\mathbf{4}}$ & $\mathbf{P}_{\mathbf{5}}$ \\
\hline Suhu & $27,5-27,7$ & $27,5-28,2$ & $27,6-27,9$ & $27,5-27,9$ & $27,5-27,9$ \\
$\mathrm{pH}$ & $6,5-7,0$ & $6,5-7,0$ & $6,5-7,0$ & $6,5-7,0$ & $6,5-7,0$ \\
$\mathrm{DO}$ & $5,48-8,70$ & $5,45-7,00$ & $5,37-7,00$ & $5,28-7,4$ & $5,35-7,41$ \\
$\mathrm{NH}_{3}$ & $0,014-0,064$ & $0,011-0,098$ & $0,009-0,043$ & $0,007-0,085$ & $0,009-0,085$ \\
$\mathrm{NO}_{2}$ & $0,003-0,412$ & $0,001-0,507$ & $0,002-0,446$ & $0,001-0,340$ & $0,001-0,340$ \\
\hline Kesadahan & $24,26-35,67$ & $24,26-29,96$ & $27,11-35,67$ & $24,26-35,67$ & $24,26-27,11$ \\
\hline Alkalinitas & $21,22-31,83$ & $21,22-31,83$ & $21,22-34,87$ & $31,83-42,44$ & $21,22-42,44$ \\
\hline
\end{tabular}


Kesimpulan Perlakuan ke-5 panjang ikan 7,0-7,9 cm menghasilkan fekunditas tertinggi yaitu 81 butir pada fekunditas relatif ,dan 367 butir untuk fekunditas total. Tingkat kematangan gonad tertinggi diperoleh dari panjang ikan 7,0-7,9 cm diikuti panjang ikan 6,0-6,9 cm yaitu TKG-5. Perlu penelitian lebih lanjut tentang fekunditas dan tingkat kematangan gonad ikan Rainbow Boesmani sampai ukuran maksimal yaitu $8-9 \mathrm{~cm}$.

\section{Daftar Pustaka}

Anonymous. 2007. Ikan air tawar langka di Indonesia seri II. Direktorat Konservasi dan Taman nasional laut. Direktorat Jendral Kelautan, Pesisir dan PulauPulau Kecil. Departemen Kelautan dan perikanan. 52 hal.

Anonymous. 2015. http://s3.amazonaws.com/academia.edu.documents 31130684 /REPRODUKSI.docx [2 April 2015. 11.00 WIB]

Allen G.R., 1980. - A Generic Classification of the Rainbowfishes (Family Melanotaenidae). Rec. West. Aust. Mus.44 hal

Boesmans Rainbowfish. http://www.arkive.org / boesemans-rainbowfish /melanotaenia -boesemani/. [8 Januari 2015, 22.00]

Bastiar, N, 2011. Studi Domestikasi dan Pemijahan Ikan Pelangi Kurumoi (Melanotaenia parva) Sebagai Tahap Awal Konservasi Ex-Situ. BPPBIH. Depok. 9 hal.

Campbell, N. A. 2004. Biology. Erlangga. Jakarta. 295 hal.

Chinabut, S. Limswan, C. Kitsawat, P. 1991. Histology of the Walking Catfish, Clarias batrachus. IRDC. 93 hal.

Effendie, M.I. 1997. Metode Biologi Perikanan. Yayasan Pustaka Dwi Sri. Bogor

Effendi, H. 2000. Telaahan Kualitas Air Bagi Pengelolaan Sumberdaya dan Lingkungan Perairan. Fakultas Perikanan dan Ilmu Kelautan, IPB. Bogor. 258 hal.

IUCN Red List.1994. http://www.iucnredlist.org/details/13058/0. [8 Januari 2014]

Kadarini T, Agus M, dan Eni K. 2011. Dukungan Pembenihan Ikan Rainbow Boesemani (Melanotaenia boesemani) Terhadap Sumber Daya Ikan di Depok.

Kadarusman. 2010. Penemuan Jenis Baru Ikan Pelangi Papua Melanotaenia fasinensis dari Sorong Selatan, Penemuan Kembali M. ajamaruensis dan Status Kritis Hampir Punah M. parva di Danau Kurumoi Kabupaten Bintuni. Warta Riset Akademi Perikanan Sorong. Sorong.

KKP.go.id. 2014. Seminar Perkembangan Ikan Hias dengan Tema Sinergitas Stakeholder Mewujudkan Industrialisasi. http://www.kkp.go.id/ikanhias /index.php/news/c/99/Seminar-Pengembangan-Ikan-Hias-dengan-temaSinergitas-Stakeholder-Mewujudkan-Industrialisasi-/?category_id=1. [15.Desember 2014, pk 10.02] 
Muna, N. 2013. Teknik Pemijahan Ikan Rainbow Kurumoi Di BPPBIH. Depok. 41 hlm.

Nasution, S.H. 2000. Ikan Hias Air Tawar Rainbow. Penebar Swadaya. Jakarta

Pusey, B.J.; Arthington, A.H.; Bird, J.A. \& Close, P.G. 2001. Reproduction in Three Species of Rainbowfish (Melanotaeniidae) From Rainforest Streams in Northern Queensland, Australia. Ecology of Freshwater Fish. 87 hal

Steel RGD, Torrie JH. 1991. Prinsip dan Prosedur Statistika Suatu Pendekatan Biometrik. Jakarta. PT.Gramedia. 772 hal.

Tappin. 2010. Rainbow Fish: Their Care \& Keeping In Capasity. [http://www. rainbow fishes@ptunesnet.com.au] 493 hal

United Nation Commodity Trade Statistic Database. 2012. http://comtrade.un.org/db/ce/ceSnapshot.aspx?px=HS\&cc=03 Nopember 2014]

Wotton, R.J.1979. Energy Cost of Egg Production and Environmental of Fecundity of Teleost Fish. The Zoology Society of London. Academic Press London. 159 hal.

Woynarovich, E. \& L. Horvath. 1980. The Artificial Propagation of Warm Water Finfish, A Manual for Extention. FAO Fisheries Technical Paper. Roma, 201 hal. 